\title{
PENELITIAN PENGARUH PENAMBAHAN HDPE PADA PLASTIK FILM POLY PROPYLENA
}

\author{
Prayitno
}

\begin{abstract}
Poly Propylena and Poly Ethylena are thermoplastic material resulted from the polymerization of propylena and ethylena gas. Each of those material have spesific in physical properties. The improved properties of Poly Propylena over the some properties of Poly Ethylena are tensile strength and stress crack resistance, in the other hand Poly Ethylena have excelent properties in flexibility and tough. To improve the flexibility and tough properties of plastic film Poly Propylena can be done by the mixing of both material. In this experiment 5\% Poly Ethylena was added to the Poly Propylena to make plastik film. Experiment result show that addition of $5 \%$ HDPE to plastic film Poly Propylena cause increasing the elongation at break from $290,20 \%$ to $432,81 \%$, but $47,20 \mathrm{~kg} / \mathrm{cm}^{2}$ to $34,568 \mathrm{~kg} / \mathrm{cm}^{2}$ from $2,7450 \mathrm{~kg} / \mathrm{cm}^{2}$ to $1,9752 \mathrm{~kg} / \mathrm{cm}^{2}$ respectively.
\end{abstract}

\section{INTISARI}

Poly Propylena dan Poly Ethylena merupakan bahan-bahan thermoplastik yang dihasilkan dari polimerisasi gas Propylena dan Ethylena. Masingmasing bahan tersebut mempunyai sifat-sifat fisika yang berbeda. Poly Propylena mempunyai keunggulan dalam kekuatan tarik dan sifat retak lentur sedangkan Poly Ethylena mempunyai keunggulan dalam sifat fleksibilitas dan keuletannya. Untuk menaikkan sifat fleksibilitas dan keuletan dari bahan plastik Poly Propylena dapat dilakukan dengan mencampur kedua bahan tersebut pada perbandingan yang tepat. Pada penelitian ini dilakukan penambahan 5\% Poly Ethylena pada Poly Propylena untuk pembuatan plastik film. Dari hasil penelitian menunjukkan bahwa penambahan $5 \%$ HDPE pada plastik Poly Propylena akan menyebabkan terjadinya perubahan sifatsifat fisis sebagai berikut : naiknya perpanjangan putus dari $290,20 \%$ menjadi $432,81 \%$, penurunan kuat tarik dari $47,20 \mathrm{Kg} / \mathrm{cm}^{2}$ menjadi 34,568 $\mathrm{Kg} / \mathrm{cm}^{2}$ dan penurunan kuat sobek dari $2,7450 \mathrm{Kg} / \mathrm{cm}^{2}$ menjadi 1,9752 $\mathrm{Kg} / \mathrm{cm}^{2}$.

\section{PENDAHULUAN}

Bahan plastik merupakan polimer sintetis yang dihasilkan dengan proses polimerisasi dari monomer yang pada umumnya didapat dari hasil samping pengolahan minyak bumi. Menurut sifatnya ada dua jenis bahan plastik. (2) 
- Thermoplastik ialah bahan plastik yang bila dipanaskan menjadi lunak dan menjadi padat pada temperatur kamar, bahan ini dapat dipanaskan dan diberi bentuk berulang-ulang.

Thermosetting plastik ialah bahan yang menjalani suatu reaksi kimia dengan bantuan panas (katalis/sinar ultra violet) dan setelah dikenakan panas tak dapat diubah lagi.

aat ini telah banyak diproduksi jenis-jenis bahan plastik sesuai dengan moomer yang digunakan.

Diantara jenis plastik yang banyak digunakan adalah jenis plastik poly hylena dan poly propylena. Poly ethylena merupakan jenis plastik yang hasilkan dari polimerisasi ethylena gas yang dapat diperoleh dari gas alam aupun dari hasil samping proses pemurnian minyak bumi. Ada dua jenis ama poly ethylena yaitu poly ethylena dengan density rendah (LDPE) dan ly ethylena dengan density tinggi (HDPE).(2) Sifat-sifat fisis dari Poly thylena adalah fungsi dari tiga susunan variabel, berat molekul, berat olekul distribusi atau cabang dari rantai panjang dan rantai pendek. Caing rantai pendek akan berpengaruh pada derajat kristalisasi dan berat jes dari Poly Ethylena. Sifat-sifat fisika seperti ketahanan sobek, kuat tarik n kemuluran sangat dipengaruhi oleh berat jenis atau jumlah rantai penk dalam polimer. Poly Propylena merupakan jenis plastik hasil polimerisi propylena gas yang dapat diperoleh dari hasil samping pemurnian miak bumi.(3)

Ada perbedaan sifat dari kedua jenis plastik tersebut, plastik poly ethya mempunyai fleksibilitas dan sifat liat pada temperatur rendah yang baik, dangkan plastik poly propylena mempunyai keunggulan dalam tensile ength dan ketahanan retaknya.(3).

Untuk mengetahui apakah ada perbaikan sifat-sifat phisis dari film astik Poly Propylena dengan penambahan Poly Ethylena maka perlu diakan penelitian Penambahan Hight Density Poly Ethylena (HDPE) pada astik Film Poly Propylena.

\section{MATERI DAN METODA PENELITIAN}

\section{Materi Penelitian}

\section{Bahan}

Bahan bahan yang digunakan :

- Bahan plastik Poly Propylena

- Bahan plastik Poly Ethylena

\section{Alat}

ALat-alat yang digunakan : a. Alat proses

- Timbangan

- Mesin untuk pembuatan pellet dan film

b. Alat uji

- Alat pembuat cuplikan

- Alat uji kuat tarik

- Alat uji kuat sobek

\section{B. Metoda Penelitian}

1. Cara kerja penelitian

a. Pembuatan pellet

Pembuatan pellet dimaksudkan untuk mendapatkan hasil compounding yang lebih homogen sebelum diproses untuk pembuatan produknya. Campuran dari 95\% Poly Propylena dengan 5\% Poly Ethylena diputar dalam alat dry blending kemudian masuk dalam unit pelletizing dengan kondisi operasi :

$\begin{array}{ll}\text { - Front temperatur } & =210^{\circ} \mathrm{C} \\ \text { - Midle temperatur } & =200^{\circ} \mathrm{C} \\ \text { - Rear temperatur } & =190^{\circ} \mathrm{C} \\ \text { - Die temperatur } & =200^{\circ} \mathrm{C} \\ \text { - Tekanan } & =30 \mathrm{~kg} / \mathrm{cm}^{2} \\ \text { - Putaran extruder } & =68 \mathrm{rpm}\end{array}$

b. Pembuatan Film

Dari hasil pelletizing, kemudian dengan cara extrusi dibuat film plastik dengan kondisi operasi :

- Front temperatur

- Midle temperatur

$=240^{\circ} \mathrm{C}$

- Rear temperatur

$=230^{\circ} \mathrm{C}$

- Die temperatur

$=220^{\circ} \mathrm{C}$

$=250^{\circ} \mathrm{C}$

- Putaran extruder

$=700 \mathrm{rpm}$

c. Pengujian

Film plastik yang dihasilkan kemudian dilakukan pengujian meliputi uji :

1). Uji kuat tarik dan kemuluran arah membujur dan melintang Alat yang digunakan : mesin tensile strength. Cara kerja pengujian :

- Buat contoh uji bentuk dayung dengan ukuran ... berikut : 


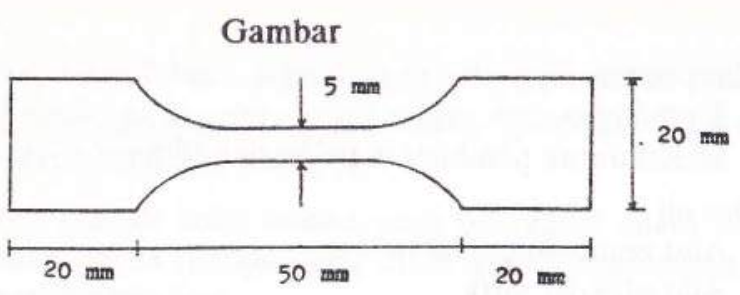

- Contoh uji dikondisikan terlebih dulu pada suhu $21^{\circ} \mathrm{C}$ pada kelembaban $65 \%$ selama 24 jam.

- Ukur contoh uji untuk tebal dan lebar sebanyak 3 kali pada bagian yang sempit.

- Kemudian pasang pada alat uji sehingga jarak penjepit 50 $\mathrm{mm}$, kemudian dilakukan penarikan.

- Catat beban yang digunakan dan pertambahan panjang pada saat putus.

\section{Perhitungan :}

Tegangan putus $=\frac{\mathrm{F}}{\mathrm{T} \times \mathrm{W}} \mathrm{Kg} / \mathrm{cm}^{2}$

Perpanjangan putus $=\frac{\text { L1 }- \text { LO }}{\text { LO }} \times 100 \%$

Dimana :

$\mathrm{F} \quad=$ beban yang diperlukan untuk menarik potongan uji sampai putus. $\mathrm{Kg}$

$\mathrm{T}=$ Ketebalan contoh uji, $\mathrm{Cm}$

$\mathrm{W}$ = Lebar pada bagian sempit contoh uji, $\mathrm{Cm}$

$\mathrm{LO}=$ Panjang awal, $\mathrm{Cm}$

$\mathrm{L} 1=$ Panjang saat putus, $\mathrm{Cm}$

2). Uji kuat sobek untuk arah melintang dan membujur. Alat yang digunakan alat kuat sobek elmendorf.

Cara kerja pengujian :

- Buat contoh uji dengan bentuk sesuai pada gambar di bawah

\section{Gambar}

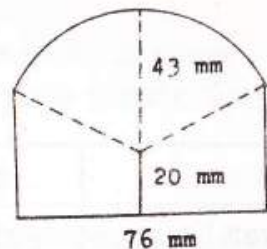

- Sebelum dilakukan pengujian contoh uji dikondisikan lebih dahulu pada suhu $21 \pm 2^{\circ} \mathrm{C}$ dengan kelembaban $50 \pm 5 \%$ selama 24 jam.

- Ukur ketebalan cuplikan dengan mikrometer.

- Letakkan cuplikan diantara 2 klem penjepit pada alat, sedemikian sehingga tepi atas cuplikan sejajar klem atas dan sobekan awal pada bagian bawah (arah sobekan terhadap pisau harus tepat).

- Tekan tombol sehingga pendulum bergerak dan cuplikan tersobek menjadi dua bagian menurut daerah sobek (jarijari sobekan)

- Catat beban yang diperlukan untuk mensobek cuplikan (dilihat pada skala)

- Periksa cuplikan yang telah tersobek, jika cuplikan tersobek diluar daerah sobek (sudut yang terbentuk dengan garis vertikal tidak $60^{\circ}$ ) maka harus di "reject"

Perhitungan :

Ketahanan sobek $=\frac{\text { Skala indikator }}{10 \times \text { luas sobekan }} \mathrm{Kg} / \mathrm{Cm}^{2}$

Luas sobekan $=$ tebal cuplikan $\mathrm{x}$ jari-jari sobekan

2. Metoda analisa data

Data pengujian sifat fisis dari plastik film diolah secara statistik dengan metoda t-test untuk dibandingkan apakah ada beda nyata sebelum dan sesudah penambahan HDPE. 


\section{HASIL PENELITIAN DAN PEMBAHASAN}

\section{Hasil Penelitian}

. Hasil uji kuat tarik $\left(\mathrm{kg} / \mathrm{cm}^{2}\right)$

\begin{tabular}{c|r|r|r|r|}
\hline \multirow{2}{*}{ Ulangan } & \multicolumn{2}{|c|}{ PP 100\% } & \multicolumn{2}{c|}{ PP 95 \% + HDPE 5 \% } \\
\cline { 2 - 5 } & $\begin{array}{c}\text { Arah bujur } \\
\text { (MD) }\end{array}$ & $\begin{array}{c}\text { Arah lintang } \\
\text { (TD) }\end{array}$ & $\begin{array}{c}\text { Arah bujur } \\
\text { (MD) }\end{array}$ & $\begin{array}{c}\text { Arah lintang } \\
\text { (TD) }\end{array}$ \\
\hline 1. & 282,60 & 49,30 & 269,44 & 32,22 \\
2. & 273.20 & 46,00 & 333,30 & 38,90 \\
3. & 258,60 & 45,40 & 282,70 & 34,11 \\
4. & 343,70 & 46,00 & 324,30 & 32,50 \\
5. & 302,30 & 49,30 & 318,30 & 35,08 \\
\hline Jumlah & 1460,40 & 236,00 & 1528,04 & 172,79 \\
Rata $^{2}$ & 292,08 & 47,20 & 305,608 & 34,558 \\
\hline
\end{tabular}

Hasil uji kemuluran (\%)

\begin{tabular}{|c|c|r|r|c|}
\hline \multirow{2}{*}{ Jlangan } & \multicolumn{2}{|c|}{ PP 100\% } & \multicolumn{2}{c|}{ PP 95 \% + HDPE 5 \% } \\
\cline { 2 - 5 } & $\begin{array}{c}\text { Arah bujur } \\
\text { (MD) }\end{array}$ & $\begin{array}{c}\text { Arah lintang } \\
\text { (TD) }\end{array}$ & $\begin{array}{c}\text { Arah bujur } \\
\text { (MD) }\end{array}$ & $\begin{array}{c}\text { Arah lintang } \\
\text { (TD) }\end{array}$ \\
\hline 1. & 320,31 & 7,81 & 437,50 & 32,22 \\
2. & 187,50 & 7,81 & 476,56 & 38,90 \\
3. & 250,00 & 7,81 & 375,00 & 34,11 \\
4. & 359,37 & 7,81 & 453,12 & 32,50 \\
5. & 335,43 & 7,81 & 421,87 & 35,08 \\
\hline umlah $_{\text {Rata }}^{2}$ & 1452,61 & 39,05 & 2164,05 & 172,79 \\
\hline
\end{tabular}

Hasil uji kuat sobek $(\mathrm{kg} / \mathrm{cm} 2)$

\begin{tabular}{|c|c|c|c|c|}
\hline \multirow{2}{*}{ Ilangan } & \multicolumn{2}{|c|}{ PP 100\% } & \multicolumn{2}{c|}{ PP 95 \% + HDPE 5 \% } \\
\cline { 2 - 5 } & $\begin{array}{c}\text { Arah bujur } \\
\text { (MD) }\end{array}$ & $\begin{array}{c}\text { Arah lintang } \\
\text { (TD) }\end{array}$ & $\begin{array}{c}\text { Arah bujur } \\
\text { (MD) }\end{array}$ & $\begin{array}{c}\text { Arah lintang } \\
\text { (TD) }\end{array}$ \\
\hline 1. & 1,2458 & 2,6578 & 1,0570 & 1,9380 \\
2. & 1,0853 & 2,8262 & 0,9807 & 1,9488 \\
3. & 1,2029 & 3,0371 & 1,0260 & 1,8200 \\
4. & 1,2458 & 2,5463 & 1,9000 & 2,0904 \\
5. & 1,2029 & 2,6578 & 0,9910 & 2,0787 \\
\hline umlah $_{\text {Rata }}^{2}$ & 5,9827 & 13,7252 & 5,9547 & 9,8759 \\
\hline
\end{tabular}

Majalah Barang Kulit, Karet dan Plastik

\section{B. Pembahasan}

Dari analisa data secara statistik dengan metoda $\mathrm{T}$ test diketahui bahwa penambahaxi 5\% HDPE pada plastik film Poly Propylena menunjukkan hal-hal sebagai berikut :

a. Sifat ketahanan tarik

Uji kuat tarik menunjukkan tidak adanya beda nyata antara kuat tarik plastik film Poly Propylena sebelum dan sesudah penambahan 5\% HDPE untuk arah bujur, terlihat dari t hitung $=0,9468$ yang lebih kecil dari $\mathrm{t}$ tabel $=2,7760$, hal tersebut kemungkinan dikarenakan bahan plastik poly propylena dan bahan plastik HDPE mempunyai sifat kuat tarik yang tidak berbeda, sehingga penambahan 5\% HDPE tidak berpengaruh pada sifat tarik poly propylena.

Untuk kuat tarik arah melintang, ternyata penambahan 5\% HDPE akan menyebabkan penurunan kuat tarik, hal tersebut kemungkinan disebabkan kurang kuatnya ikatan antara molekul HDPE dengan molekul Poly Propylena. Analisa statistik menunjukkan $\mathrm{t}$ hitung = 7,5793 lebih besar dari t tabel 2,776.

b. Sifat kemuluran

Uji kemuluran menunjukkan adanya kenaikan yang nyata untuk kemuluran dengan penambahan 5\% HDPE, analisa statistik menunjukkan t hitung $=3,8065$ yang lebih besar dari t tabel 2,776. Hal tersebut kemungkinan disebabkan adanya sifat liat dari bahan plastik HDPE yang lebih baik dari sifat liat poly propylena, sedangkan untuk arah melintang tidak menunjukkan adanya perbedaan.

c. Sifat ketahanan sobek

Uji kuat sobek arah membujur menunjukkan tidak adanya beda nyata sebelum dan sesudah penambahan HDPE 5\%, sedangkan untuk arah melintang menunjukkan penurunan kuat sobek yang nyata dari 2,7450 $\mathrm{kg} / \mathrm{cm}^{2}$ menjadi $1,9752 \mathrm{~kg} / \mathrm{cm}^{2}$, hal tersebut kemungkinan disebabkan kurang kuatnya ikatan antar molekulnya setelah proses.

\section{KESIMPULAN}

Dari hasil penelitian dapat disimpulkan bahwa penambahan 5\% HDPE pada plastik film poly propylena akan menunjukkan sifat-sifat sebagai berikut :

1. Menurunnya kuat tarik arah melintang dari $47,20 \mathrm{~kg} / \mathrm{cm}^{2}$ menjadi $34,568 \mathrm{~kg} / \mathrm{cm}^{2}$, sedangkan kuat tarik arah membujur tidak menunjukkan adanya perbedaan.

2. Naiknya kemuluran plastik film poly propylena dari $290,52 \%$ menjad $432,81 \%$, sedangkan kemuluran arah lintang tidak menunjukkan adanya perbedaan. 
3. Menurunnya kuat sobek arah melintang dari $2,7450 \mathrm{~kg} / \mathrm{cm}^{2}$ menjadi $1,9752 \mathrm{~kg} / \mathrm{cm}^{2}$, sedangkan kuat sobek arah bujur tidak menunjukkan adanya perubahan.

\section{KEPUSTAKAAN}

1. Book of ASTM Standart with Related Material (1968), Plastic General Method of Testing, part 27, Philadelphia 19103

2. Brydton, J.A. (1975), Plastik Material, Newest-Britter Worth, London.

3. Richardson, Terry, A. Modern Industrial Plastik, Howard W Sons and Co Inc, Indianapolis, Kansas City, New York.

\section{LAMPIRAN}

Contoh perhitungan statistik metoda $t$ test untuk membandingkan kuat tarik arah membujur plastik film poly propylena.

\begin{tabular}{|c|r|r|r|}
\hline Ulangan & PP $100 \%$ & PP 95\% + HDPE 5\% & \multicolumn{1}{|c|}{ I - II } \\
\hline 1. & 282,60 & 269,44 & 13,16 \\
2. & 273,20 & 333,30 & $-60,10$ \\
3. & 258,60 & 282,70 & $-24,10$ \\
4. & 343,70 & 324,30 & 19,40 \\
5. & 302,30 & 318,30 & $-16,00$ \\
\hline & 1460,40 & 1528,04 & $-67,64$ \\
& $\mathrm{X}_{1}=292,08$ & $\mathrm{X}_{2}=305,608$ & \\
\hline
\end{tabular}

$$
\begin{aligned}
\text { CF } & =\left|\frac{I-I I}{n}\right|=\left|\frac{-67,64}{5}\right|^{2}=915,0339 \\
\text { SS } & =(13,16)^{2}+(-60,10)^{2}+\ldots \ldots+(-16,00)^{2}-C F \\
& =4998,3656-915,0339=4083,3317
\end{aligned}
$$$$
\text { Ms }=\frac{\text { SS }}{\mathrm{n}-1}=\frac{4083,3317}{4}=1020,8329
$$$$
\text { Sd }=\sqrt{ } \text { Ms }=\sqrt{ } 1020,8329=31,9505
$$$$
\mathrm{SED}=\frac{\mathrm{Sd}}{\sqrt{v}}=\frac{31,9505}{\sqrt{5}}=14,2887
$$$$
\text { thitung }=\left|\frac{X_{1}-X_{2}}{\text { SED }}\right|=0,9468
$$

${ }^{\mathrm{t}} 5 \%$ (tabel) $=2,7760$

thitung ${ }^{<t}$ tabel

Kesimpulan : tidak berbeda nyata 